Article

\title{
Novel Pesticide Risk Indicators for Aquatic Organisms and Earthworms
}

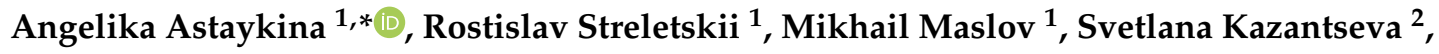 \\ Elizabeth Karavanova ${ }^{1}$ and Victor Gorbatov ${ }^{3}$ \\ 1 The Soil Science Faculty, Lomonosov Moscow State University, 119991 Moscow, Russia; \\ streletskiyrostislav@mail.ru (R.S.); maslov.m.n@yandex.ru (M.M.); karavanovaei@mail.ru (E.K.) \\ 2 The Faculty of Foreign Languages and Area Studies, Lomonosov Moscow State University, 119991 Moscow, \\ Russia; svetix26199@mail.ru \\ 3 LLC Centre for Ecopesticide Research, 119991 Moscow, Russia; gvs@penreg.ru \\ * Correspondence: astaikina-anzhel@mail.ru; Tel.: +7-(903)-112-73-02
}

Received: 14 June 2020; Accepted: 22 July 2020; Published: 24 July 2020

\begin{abstract}
There are many approaches of pesticide risk assessment. Despite their variation in difficulty and information complexity, all of them are intended to predict the actual pesticide risk as accurately as possible, i.e., to predict the behavior and hazard of a pesticide in the environment with high precision. The aim of this study was to develop a risk indicator of pesticide's negative impact on soil and aquatic organisms. The developed pesticide risk indicator constitutes the sum of points of acute toxicity exposure ratio, long-term toxicity exposure ratio, and the bioconcentration factor. To develop the indicator, mathematical models were used; the input data included the soil and climate conditions of a specific region. Combining the data of pesticide toxicity in the environment allowed for a more accurate risk assessment in terms of using plant protection products. The toxicity and behavior in soil and water of 200 widespread pesticides were studied. It could be concluded that a mathematical model, PEARL 4.4.4, calibrated for region-specific soil-climate conditions, provides a relevant description of the natural translocation and decomposition of pesticides in soils. In addition, the output data of this model can be applied to calculate the risk indicators. The combination of these parameters with pesticide toxicity for non-target groups of organisms allows the risk indicator to be a universal tool for predicting the negative impact of pesticides on the environment at the regional level.
\end{abstract}

Keywords: aquatic organisms; earthworms; modeling; pesticide indicator; pesticide risk

\section{Introduction}

Over two million tons of pesticides are applied annually around the world [1]. Although many countries have taken pesticide application under control, the hazard of their negative impact on non-target organisms and ecosystems is not fully ensured [2,3]. There are three possible ways to decrease the negative impact of the applied pesticides: (1) improving the monitoring system of pesticide impact on the environment; (2) assessing the risk of pesticide application using the soil-climate conditions of a specific region; and (3) developing the pesticides of minimum toxicity.

In many countries, environmental assessment is crucial for a pesticide to be officially registered [4,5]. The assessment includes the hazard classification of a pesticide and the determination of its negative impact [6]. Environment assessment tools are constantly improving: new databases of eco-toxicological pesticide properties [7] and models of pesticide risk assessment [8-10] are being developed. The developed risk indicators can differ in assessment difficulty and information complexity. One of the simplest indicators is the quantity of active ingredients (QA). It considers only the quantity of kilograms of pesticide active substances applied on the territory [11], whereas aggregate indicators 
such as the load index (LI) considers both the application rate and a wide range of medical and environmental hazards for every pesticide [12,13]. Simple indicators are user-friendly for the economic assessment of pesticide application [14-16], while environmental assessment purposes require more reliable and informative aggregate risk-based indicators. Various methods of data aggregation are used for grouping heterogeneous data into one convenient indicator, i.e., a risk indicator [17]. Currently, dozens of such indicators have been proposed, which makes it difficult to classify and select the most appropriate ones. The first attempts to develop environmental indicators were attributed to the assessment of the overall harm to the environment, including various non-target organisms [18,19]. For example, Higley and Wintersteen [20] were the first to calculate the economic damage caused by pesticide application. In 1993, appeared the first guidelines for the comprehensive risk assessment of pesticide contamination in water bodies [21]. By the end of the 20th century, nine environmental risk indicators had already been developed [22-25]. The European Union project «CAPER» (Concerted Action on Pesticide Environmental Risk) classified the data on the indicators outlining their advantages and disadvantages. The eight pesticide risk indicators differed in regard to the compartments, effects and methods used to calculate the environmental impact scores [26]. The use of scoring to reflect environmental risk or performance instead of more realistic models of predicted pesticide concentrations is a common disadvantage of these indicators (all indicators produce a score to reflect environmental risk or performance). In the USA, environmental risk indicators were developed within the project Consortium for Integrated Pest Management (CIPM) devoted to integrated pest management (IPM) [27]. Later, Thomas J. Greitens [28] on the basis of the experimental data (two years of pesticide application data from four farms) estimated the validity and reliability of eight pesticide risk indicators developed throughout Europe and the United States. Only three of the nine studied indicators were revealed to have been validated: SYNOPS (Germany), the multi-attribute toxicity factor (USA), and the environmental impact quotient (USA).

Currently, there is a high development of pesticide risk indicators for individual environmental media compartments (water, soil, air) and various groups of non-target organisms. This results from methodological difficulty in considering the numerous factors of the environment to assess the risk of a pesticide and its negative impact on the environment as a whole. Therefore, the three aquatic risk indicators developed by the Organization for Economic Cooperation and Development (OECD) under the National Action Plan to reduce the risk from the use of plant protection products (1998-2002) were REXTOX, ADSCOR and SYSCOR [29]. To calculate these indicators, the scoring and mechanistic approaches were applied. The ratio of exposure to toxicity (REXTOX) is based entirely on the mechanistic approach. The additive scoring (ADSCOR) uses a simple scoring system but includes some original (unscored) variables. The synergistic scoring (SYSCOR) uses a more complex scoring system and some original (unscored) variables [30]. However, all of these three indicators have one common drawback. They require a complex calculation for a pesticide concentration in a water body. The concentration should be calculated manually by specific equations excluding the soil and climate conditions of the locality. Therefore, using such indicators makes the prediction of pesticide's negative impact far less relevant [31]. Processes of pesticide transformation and migration should be included when calculating the aggregate risk indicator as they depend on the soil and climate conditions of the area of pesticide application [32]. The use of mathematical modeling makes it possible to accurately predict a pesticide's fate in the environment. Furthermore, the simulation has benefits over other methods of studying this matter in economic terms and allows considering a wide range of soil properties, as well as hydrological, climatic, agrotechnical, and other parameters. Therefore, mathematical models of pesticide behavior have recently been used for tackling issues related to the registration of pesticides in EU countries and the United States [33]. In particular, models PEARL 4.4.4 and STEP 1-2 are used to predict pesticide concentrations in soils, ground and surface water in the European Union and in the Russian Federation.

The aim of this study was to develop a risk indicator of pesticide's negative impact on soil and aquatic organisms based on the sum of points of acute toxicity exposure ratio, long-term toxicity 
exposure ratio, and the bioconcentration factor $(\mathrm{BCF})$ as well as on using mathematical models whose input data included the soil and climate conditions of a specific region.

\section{Materials and Methods}

\subsection{The PEARL 4.4.4 and STEP 1-2 Models}

To predict the concentrations, we used the chromatographic flow model PEARL 4.4.4 which is based on the differential convection-diffusion equation of mass transport in soil [34]. The main parameters of the model are presented in Table 1.

Table 1. Parameters of the PEARL 4.4.4 model.

\begin{tabular}{|c|c|c|}
\hline \multirow{3}{*}{ Input Files } & Soil & $\begin{array}{l}\text { The mass content of organic matter }(\mathrm{kg} / \mathrm{kg}) \text {, the dry bulk } \\
\text { density }\left(\mathrm{kg} / \mathrm{m}^{3}\right), \mathrm{pH} \text {, the textural distribution, parameters of } \\
\text { the van Genuchten functions. }\end{array}$ \\
\hline & Pesticide & $\begin{array}{c}\text { Coefficient of equilibrium sorption on organic } \\
\text { matter-Kom }(\mathrm{L} / \mathrm{kg}) ; \text { half-life in equilibrium domain at } \\
\text { reference temperature-DT50 }(\mathrm{d}) \text {; saturated vapor pressure at } \\
\text { reference temperature }(\mathrm{Pa}) \text {; solubility in water at reference } \\
\text { temperature }(\mathrm{kg} / \mathrm{L}) ; \text { application rate }(\mathrm{kg} \text { a.s./ha); } \\
\text { application methods. }\end{array}$ \\
\hline & Weather data & $\begin{array}{l}\text { File with weather: minimum and maximum air temperature, } \\
\text { precipitation, solar radiation, wind speed, vapor pressure. }\end{array}$ \\
\hline \multirow[b]{2}{*}{ Output Files } & Water balance & Flux of water in run off $(\mathrm{mm})$, soil evaporation $(\mathrm{mm})$. \\
\hline & Pesticide & $\begin{array}{l}\text { Concentration in the soil system }(\mu \mathrm{g} / \mathrm{kg}) \text {; total pesticide mass } \\
\text { flux and accumulated mass flux at the lower boundary; } \\
\text { substance concentrations in the liquid and solid phase; mass } \\
\text { flux of pesticide volatilization through the soil surface. }\end{array}$ \\
\hline
\end{tabular}

Half-life (DT50): the time it takes for an amount of a compound to be reduced by half through degradation.

Experimental supplies of this model are the physicochemical soil properties and climate data of the regions of pesticide application. This is collectively called a standard model scenario. It determines the prediction quality and correlation of the predicted pesticide concentrations to the concentrations in the field. In this study, we used the standard scenarios for the Moscow region (central part of the European Russia). The parameters of the standard scenario are shown in Table 2.

Table 2. Parameters of the standard scenario of the PEARL 4.4.4 model for the Moscow region.

\begin{tabular}{|c|c|}
\hline Parameter & Value \\
\hline $\begin{array}{c}\text { Organic matter }(\%) \\
0-25 \mathrm{~cm}\end{array}$ & 1.5 \\
\hline $\mathrm{pH}$ water & 5.6 \\
\hline $\begin{array}{l}\text { Texture class (USDA) } \\
\quad 0-25 \mathrm{~cm}\end{array}$ & Silty loam \\
\hline Soil bulk density, $\mathrm{g} / \mathrm{cm}^{3}$ & 1.2 \\
\hline Average annual air temperature $\left({ }^{\circ} \mathrm{C}\right)$ & 3.6 \\
\hline Average annual precipitation (mm) & 548 \\
\hline
\end{tabular}

USDA: United States Department of Agriculture.

The STEP 1-2 model [35] was used to predict the pesticide concentrations in surface water bodies as it allows the calculation of the most relevant and time-weighted average pesticide concentrations in water for $0,1,2,4,7,14,21,28,42,50$ and 100 days after its application. A water body with a depth of $30 \mathrm{~cm}$ and a bottom sediment thickness of $5 \mathrm{~cm}$ was used as a model. The calculation also considered such factors as pesticide interception by crop, pesticide air drift to the surface of the water body during the field treatment and its migration into the water body due to surface runoff and drainage from soil. 
To predict the pesticide concentrations in surface waters and in soils, we used the recommended single application rates of pesticides for the main crops growing in Russia. If the pesticide is applied only for seed treatment, its application rate was calculated considering the standard quantity of seed per hectare.

The Procedure of Testing the PEARL 4.4.4 Model and the Assessment of the Model Simulation

To assess the adequacy of the PEARL 4.4.4 model in the soil-climate conditions of the Moscow region, we conducted a field column experiment with metribuzin as it has a low sorption capacity $\left(\mathrm{K}_{\mathrm{OC}}=38\right)$ and a high solubility $(\sim 5 \mathrm{~g} / \mathrm{L})$. Physicochemical properties of soddy-podzolic soil are presented in Supplementary Table S1: Parameters of the soddy-podzolic soil.

Polypropylene pipes (with an inner diameter of $100 \mathrm{~mm}$ and a length of $300 \mathrm{~mm}$ ) were driven into the soil located on a flat field section devoid of plants. The pipes were placed from each other at a distance of about $2 \mathrm{~m}$ (8 pipes in total). A weighed sample of the soil treated with metribuzin (at a rate of $0.98 \mathrm{~kg} / \mathrm{ha}$ ) was evenly poured onto the soil surface in the pipe, slightly compacted and covered with a $10 \mathrm{~mm}$ layer of untreated soil. The soil samples for analysis were taken after 7, 14, 28, 56,84 and 120 days. Under laboratory conditions, the soil column was divided into three layers of $10 \mathrm{~cm}$ in height. The analysis of metribuzin residues was carried out according to the previously described procedure [2] by high-performance liquid chromatography (HPLC) using an Agilent 1200 series instrument with a quadrupole-time-of-flight mass spectrometric detector (6520 Accurate-Mass Q-TOF LC/MS Agilent Technologies; the source of ionization was electrospray (+); column Phenomenex Hydro-RP C18 $4 \mu \mathrm{m}$ $4.6 \times 100 \mathrm{~mm}$; the mobile phase was water and methanol with the addition of formic acid $(10 \mathrm{mM})$, and the volume of the injected sample was $5 \mu \mathrm{L}$ ).

To improve the prediction accuracy and achieve the convergence of the measured and simulated values, the PEARL 4.4.4 model was calibrated for the parameters of soil water regime and for the parameters of the selected pesticides. As shown in the specialized publications [36], to approximate the soil water retention curve (SWRC), the physical parameters of the van Genuchten equation had the greatest influence on prediction accuracy. The assessment of the models' sensitivity showed that the parameters of the van Genuchten equation for the approximation of the SWRC had the highest effect on the output state variable (the flow volume). In this work, we used the experimental soil parameters of the SWRC approximation (by the van Genuchten equation) for the soddy-podzolic soil. These data were provided by E.V. Shein [37].

\subsection{Data on Pesticide Toxicity and Bioaccumulation}

We collected data for 200 active substances of pesticides (herbicides, fungicides, and insecticides) commonly applied worldwide [38]. The international database PPDB (Pesticide Property Data Base), which was based on the results of registration tests and other scientific publications, was the primary data source of the physicochemical and eco-toxicological properties of pesticides [39]. We used the data on acute and chronic toxicity for fish (the typical example is Oncorhynchus mykiss), aquatic invertebrates (Daphnia magna), algae (mainly Selenastrum capricornutum), and earthworms (Eisenia foetida). For fish we also used the BCF values presented in the database. Unlike the BCF values for aquatic organisms, the $\mathrm{BCF}$ values for earthworms are missing from the database. The $\mathrm{BCF}$ was calculated using the data on the octanol-water partition coefficient (Kow) by the equation [40]:

$$
\log \mathrm{BCF}=1.0 \times \log \mathrm{K}_{\mathrm{ow}}-0.6\left(n=100, r^{2}=0.91\right)
$$

The application rates and physicochemical and eco-toxicological properties of 200 active substances of pesticides were added as a Supplementary Table S2: Physicochemical and eco-toxicological properties of pesticides. 


\subsection{Risk Assessment of Pesticide Application for Aquatic and Soil Organisms}

The risk of acute and chronic pesticide toxicity for earthworms and aquatic organisms was quantitatively characterized using the ratios of pesticide toxicity to its predicted concentrations in soil and water, respectively. According to the international guidelines [41], the acute toxicity exposure ratio (TER) of pesticides is recognized to be low if $\mathrm{LC}_{50}\left(\mathrm{EC}_{50}\right) /$ predicted environmental concentrations (PEC)max $\geq 100$ for fish and invertebrates, and $\geq 10$ for algae. Long-term TER is recognized to be low if NOEC/PEC $21 \geq 10$. For earthworms, the acute TER of pesticides is considered to be low in the case of $\mathrm{LC}_{50} / \mathrm{PEC} \max \geq 100$. Long-term TER is the lowest at NOEC/PEC $56 \geq 5$ [42].

A step-by-step scheme of procedures to determine the hazard assessment, toxicity exposure ratios and the ratings of pesticide indicators for aquatic organisms and earthworms is presented in Figure 1.

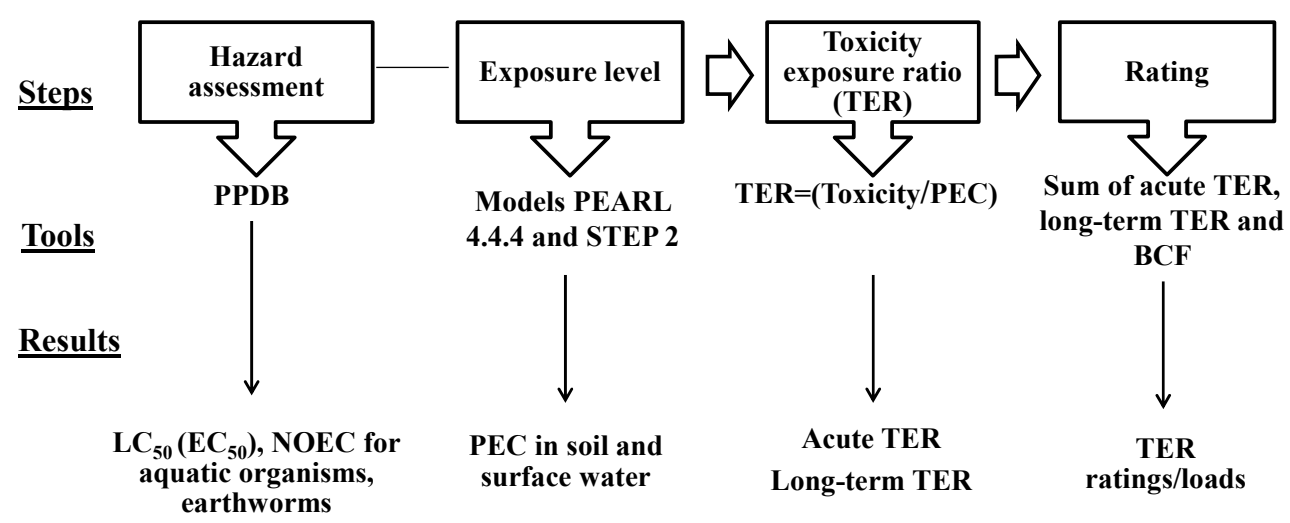

Figure 1. A step-by-step scheme of the hazard assessment and toxicity exposure ratios (TER) of pesticides for aquatic organisms and earthworms. LC/EC: lethal concentration; NOEC: no observed effect concentration; BCF: bioconcentration factor; PEC: predicted environmental concentration.

The comparative assessment of pesticides is complicated by large amounts of input data (toxicity indicators for various groups of aquatic and soil organisms) which characterize the different aspects of pesticides' negative impact on non-target organisms. Therefore, to synthesize and reduce the input information, we used the following techniques:

1. Using data on pesticide toxicity for earthworms and only for the most sensitive group of aquatic organisms;

2. Transforming the indicators of pesticide toxicity and pesticide concentration into acute and long-term toxicity exposure ratios [21]: $\mathrm{TER}_{\text {acute }}=\mathrm{LC}_{50}\left(\mathrm{EC}_{50}\right) / \mathrm{PEC}_{\max }$, where $\mathrm{LC}_{50}$ or $\mathrm{EC}_{50}$ is 50 percent of the lethal concentration, and $\mathrm{PEC}_{\max }$ is the maximum predicted pesticide concentration in soil and surface water: $\mathrm{TER}_{\text {long-term }}=\mathrm{NOEC} / \mathrm{PEC}_{56}$ or 21 days, where NOEC is the ineffective observed pesticide concentration, and the $\mathrm{PEC}_{56}$ and $\mathrm{PEC}_{21}$ days are the weighted average predicted pesticide concentrations in soil per 56 days and in water per 21 days;

3. The numerical values of these indicators are converted into points as follows: (a) all the pesticides are ranked for each indicator value from the min TER to max TER (acute and long-term) and from max BCF to min BCF; (b) 20 pesticides are selected from these three ranked lists with the corresponding numerical values of each indicator; (c) if the pesticide occupies the first line in any of the three indicators, then the numerical value of this indicator is converted to 1 point; (d) if the pesticide is in the bottom line of the rating, the value is converted to 20 points;

4. The points for each of the three indicators are summarized and the pesticides are again ranked from $\min$ to $\max$, where min is a pesticide with high environmental risk.

Thus, to synthesize the rated risk indicators of acute and chronic toxicity and bioconcentration factors of pesticides, we added the points together, which allowed us to compile the ratings of the ecological risk indicators of pesticides for earthworms and aquatic organisms. Therefore, the environmental risk indicator of pesticides is the sum of points of $\mathrm{TER}_{\text {acute }}+\mathrm{TER}_{\text {long-term }}+\mathrm{BCF}$. 


\subsection{Statistical Processing of the Results}

Statistical data analysis was conducted in Excel and STATISTICA 10 programs. The results shown in the charts and text are given as the mean values and the standard deviation (SD) is indicated, unless noted otherwise.

Data visualization on the risk assessment of pesticide negative impact was conducted in the software framework R using the package 'ggplot2'. The verification of statistical hypotheses was performed at significance 0.05 unless noted otherwise.

\section{Results}

\subsection{Validation of the PEARL 4.4.4 Model}

We conducted the calibration of the PEARL 4.4.4 model before the start of the behavior modeling of 200 pesticides in soddy-podzolic soils. The calibration included two stages: the first stage consisted in the validation of the model for the water regime parameters of soddy-podzolic soil; the second stage involved the calibration for the physicochemical properties of the pesticides. Empirical data for model calibration and quality assessment of the prediction were obtained through field research and are presented in Supplementary Table S3: Metribuzin residual amount in soddy-podzolic soil. Figure 2 shows the dynamics of the residual quantity of metribuzin in soddy-podzolic soil.

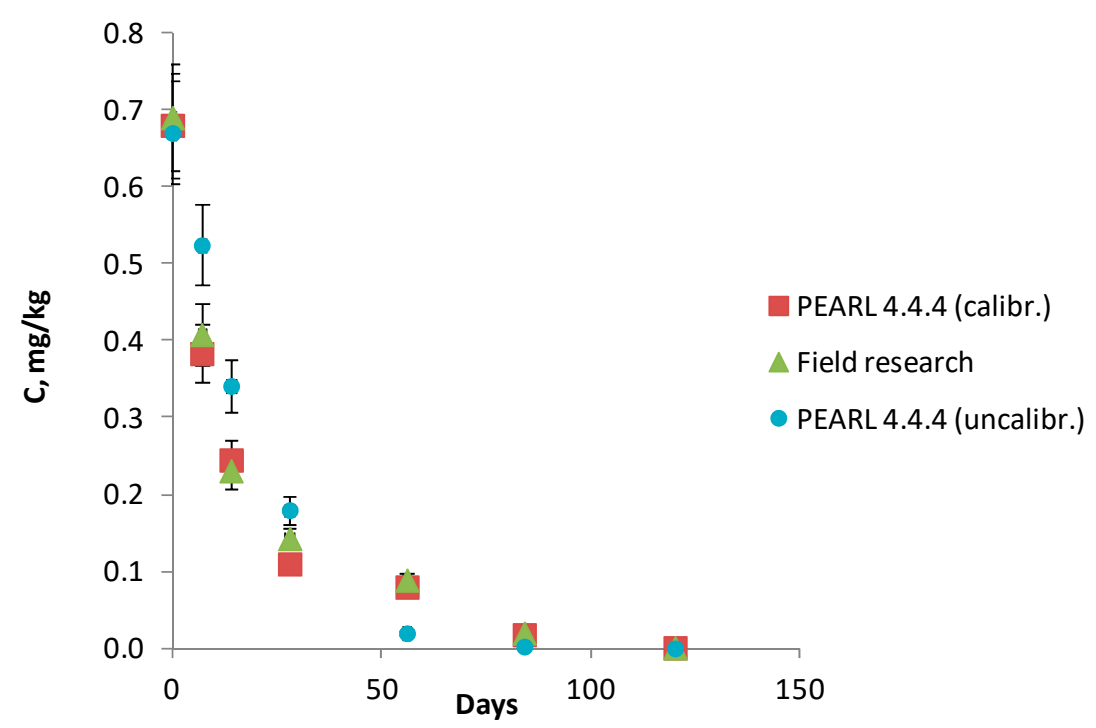

Figure 2. Dynamics of the residual amount of metribuzin in soddy-podzolic soil. Error bars indicate the confidence interval at $\alpha=0.05$.

To draw the diagrams in Figure 2, we used two types of data: the experimental data and the data of mathematical prediction based on the PEARL 4.4.4 model. The data of mathematical prediction were fixed before the model calibration, and then after the calibration for comparison. Figure 2 shows that the uncalibrated model overestimates the metribuzin residues by $6-18 \%$ in the layer $0-20$ on the 7 th, 14 th and 28 th day and underestimates the metribuzin concentration by $8 \%$ on the 56 th day as compared to the calibrated model and the experimental data. After calibrating the model for water and physicochemical pesticide properties, we achieved the convergence of the predicted and real values (Figure 2), which is also proved by statistical criteria.

Figure 3 provides the distribution diagram of the errors in the modeling for the calibrated model PEARL 4.4.4. 


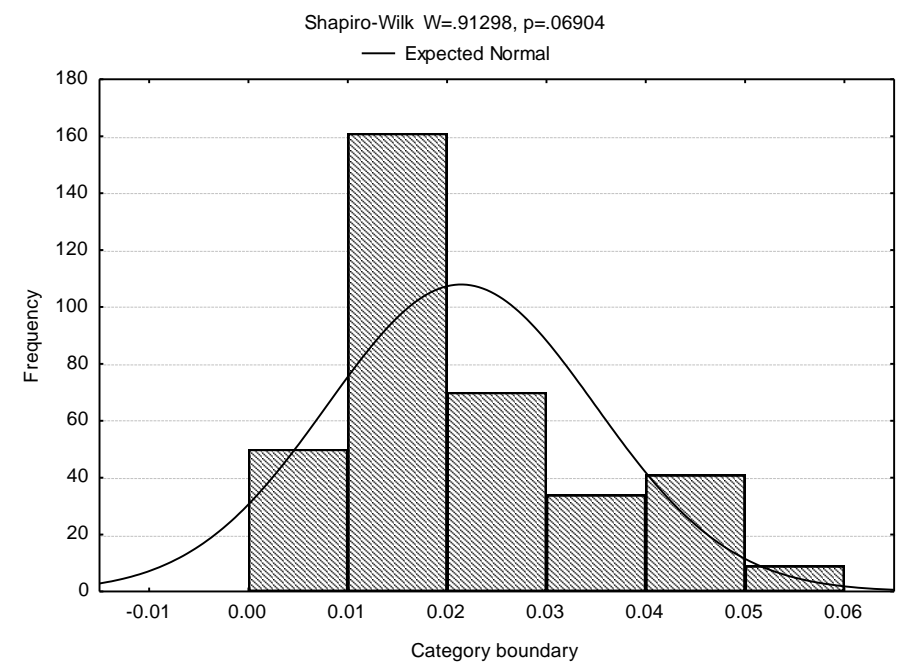

Figure 3. Distribution diagram of the errors in the modeling of the metribuzin concentration in soddy-podzolic soil.

The Shapiro-Wilk criterion is 0.91 at the significance level of $p=0.07$ (the hypothesis is accepted at $p>0.05$ ) which leads to the conclusion that the given distribution is attributed to the distribution of normality. However, the mean magnitude of error is non-zero. Consequently, this considerably increases the risk of errors in the prediction.

Statistical data analysis resulted from the preliminary calibrated model PEARL 4.4.4 which revealed that a standard error of the mean error magnitude in modeling approached zero.

Mean error, standard deviation, and the standard error of the mean error in modeling are presented in Figure 4.

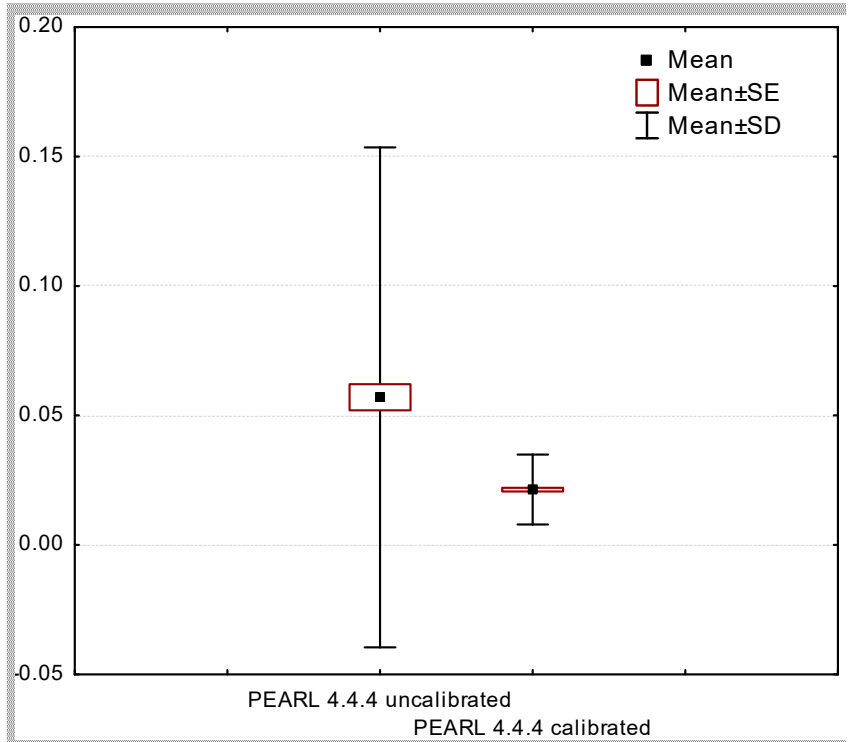

Figure 4. Characteristics of the statistical error distribution in the modeling of the metribuzin concentration in soddy-podzolic soil.

Results of the dependence analysis of the experimental values on the predicted ones are shown in Figure 5. 


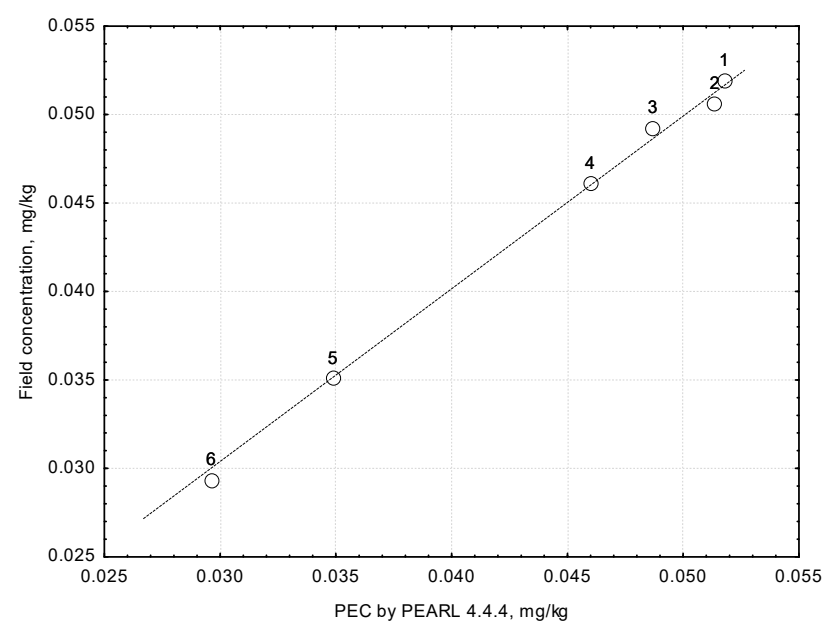

Figure 5. Dependence of the real values on the PEARL 4.4.4 predicted values.

In theory, the chart (Figure 5) should contain an angle bisector, i.e., the convergence of the real and predicted values, but in this case the points are on the opposite sides of the straight line, indicating the errors. However, the final conclusion on the error presence/absence can be made only after the dependence analysis of the approximation errors on the PEARL 4.4.4 predicted value (Figure 6).

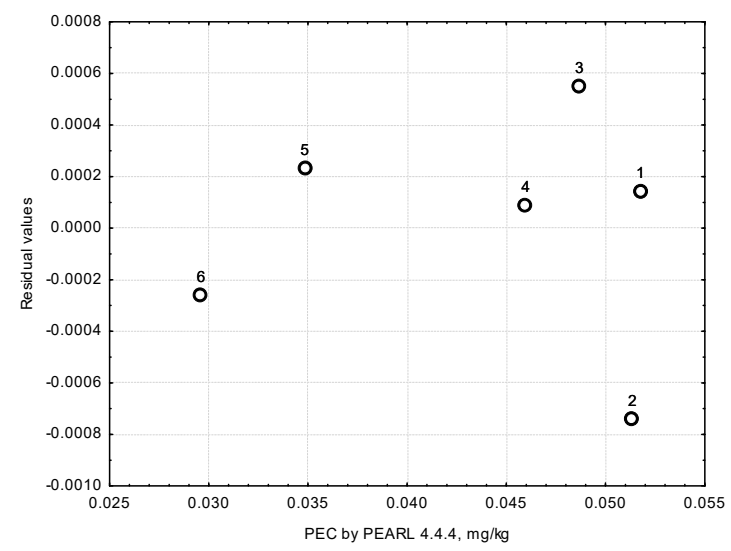

Figure 6. Dependence of error distribution on the PEARL 4.4.4 predicted value.

As shown in Figure 6, approximation errors have a random spread. Maximum random errors are shown at points 3 (approximately 0.00058) and $2(-0.00078)$. However, these errors are insignificant in value. Hence, it can be stated that systematic errors are absent in the prediction of pesticide concentration based on the PEARL model 4.4.4.

Thus, with a probability of at least $95 \%$ (significance value is 0.05 as accepted in Earth sciences) the PEARL model 4.4.4 adequately describes the migration and decomposition of pesticides in soils. The output data of this model can be applied to calculate the risk indicators.

\subsection{Predicted Environmental Concentration (PEC) of Pesticides in Soil and Water}

When the model PEARL 4.4.4 was calibrated and the prediction accuracy was assessed with statistical criteria, we conducted a mathematical modeling for 200 active substances of pesticides (herbicides, fungicides, and insecticides) which are commonly applied worldwide. The results of the modeling allowed us to obtain predicted environmental concentrations of pesticides (PEC) in the plow horizon of soddy-podzolic soil (see Supplementary Table S4: PEC in soil and surface water). We rated 200 active substances according to their concentrations. For the further research, we selected 20 pesticides of the 200 active substances. The selection criterion was the rates higher than $0.25 \mathrm{mg} / \mathrm{kg}$ ( 0 days) and higher than $0.05 \mathrm{mg} / \mathrm{kg}$ (56 days). We determined the threshold concentrations $(0.25 \mathrm{mg} / \mathrm{kg}$ 
and $0.05 \mathrm{mg} / \mathrm{kg}$ ) using the analysis of the risk values of acute and chronic toxicity of pesticides for earthworms. We did not consider the pesticides with a risk value of acute TER $>1000$ and long-term TER $>50$ (we took triggers for the TER 10 times more than that generally accepted [42] for acute TER $>100$ and long-term TER $>5$ due to the further consideration of the three factors in one risk indicator). For example, the soil with pesticide concentration $<0.25 \mathrm{mg} / \mathrm{kg}$ had acute TER values $>1000$. Figure 7 shows pesticide concentrations at the moment of their application and the weighted average concentrations in 56 days.
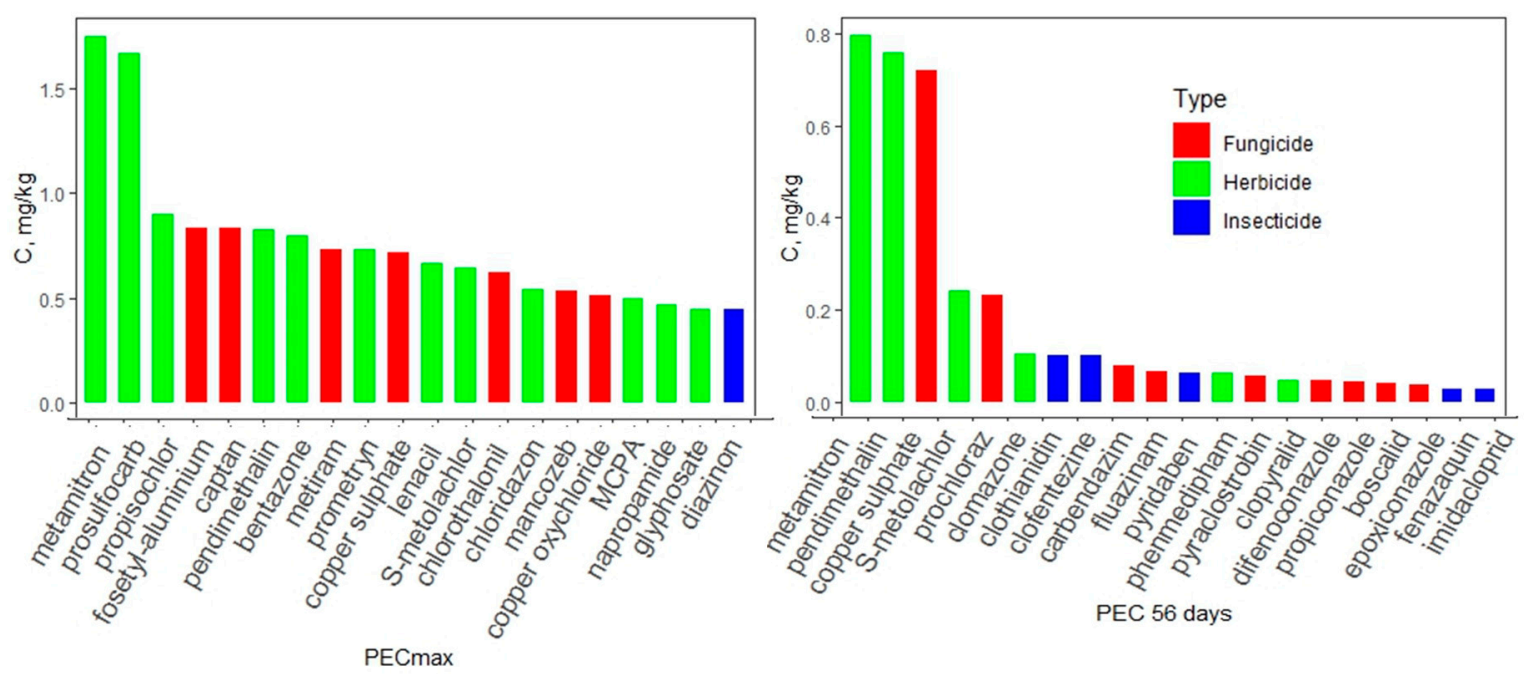

Figure 7. Rated concentrations of pesticides in soil.

The prediction based on the PEARL 4.4.4 model has shown that herbicides are concentrated in the plow layer of soddy-podzolic soil after their application (Figure 7). Moreover, the majority of fungicide residues can be found in the soil on the 56th day after the application because these substances have a high value of $\mathrm{DT}_{50}$ [39]. As shown in Figure 7, the herbicide metamitron takes the first line in the rating. This pesticide is likely to remain in high concentration at the time of application (the maximum application rate- $4.2 \mathrm{~kg} / \mathrm{ha}$ ), and 56 days after.

Predicted pesticide concentrations based on the model STEP 1-2 in surface water body are presented in Figure 8. The PEC for 200 active substances of pesticides are presented in the Supplementary Table S4: PEC in soil and surface water.
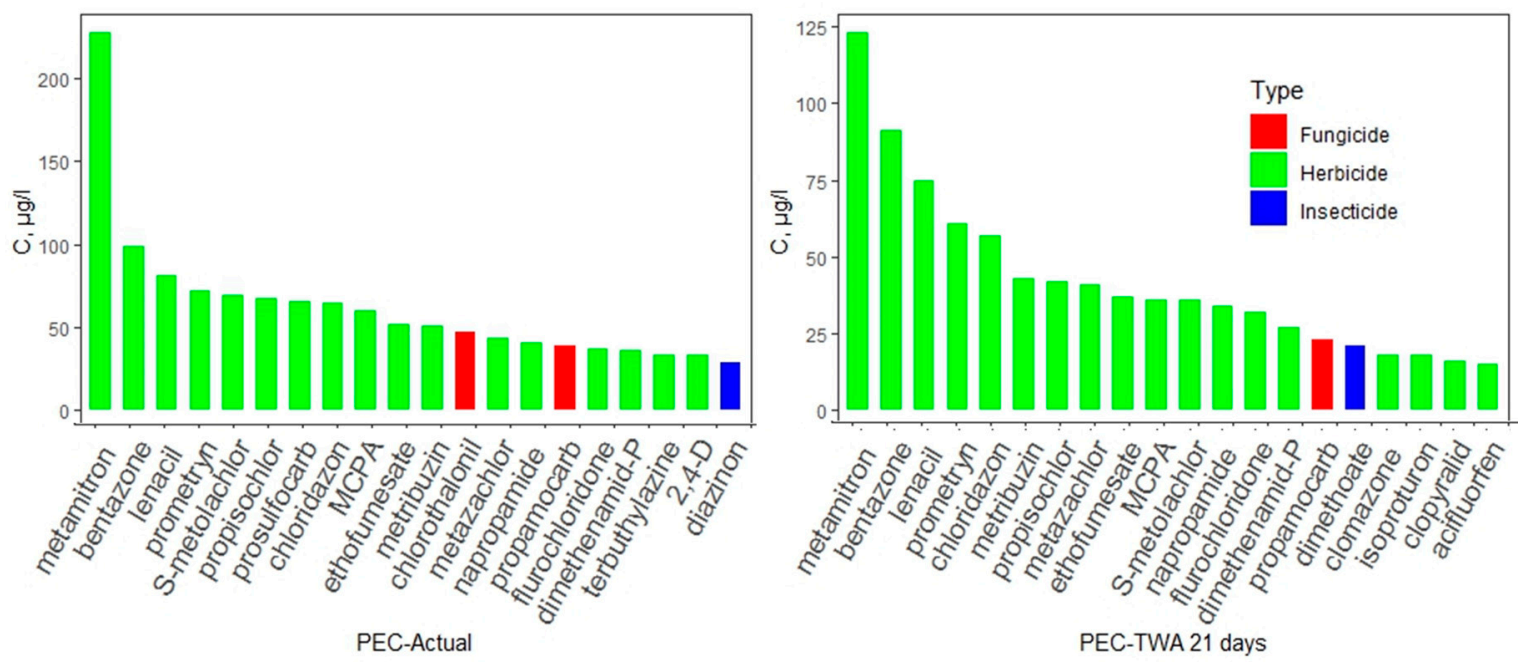

Figure 8. Rated concentrations of the pesticides in water. TWA: time weighted average. 
Surface waters become primarily polluted with herbicides according to the results of mathematical modeling. The given rating shows that herbicides take 17 positions at concentration values higher than $20 \mu \mathrm{g} / \mathrm{L}$ ( 0 days) and 18 positions with concentrations higher than $10 \mu \mathrm{g} / \mathrm{L}$ (21 days) (Figure 8). The herbicide metamitron is found to be in high concentrations in surface waters, as well as in the plow horizon of soddy-podzolic soil.

\subsection{Toxicity Assessment of Pesticides for Earthworms and Aquatic Organisms}

Figure 9 demonstrates in decreasing order the 20 most toxic pesticides for earthworms (the values of the parameters for acute and chronic toxicity $\mathrm{LC}_{50}$ and NOEC are presented, respectively).
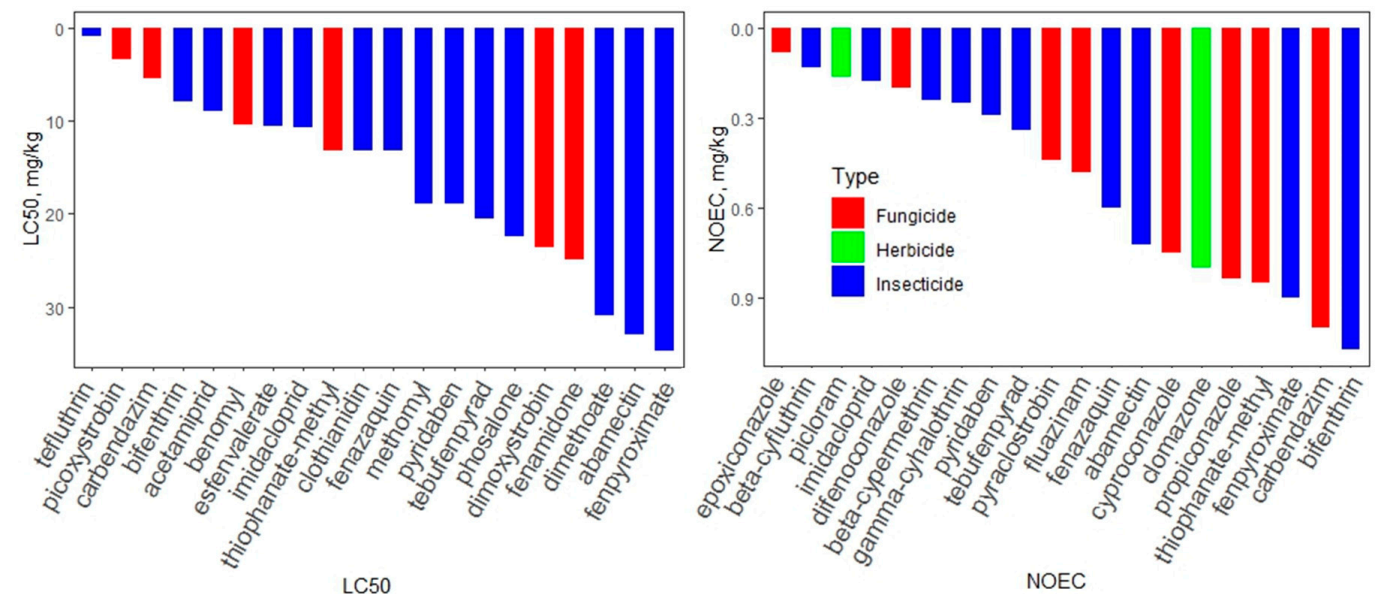

Figure 9. Ratings of the most toxic pesticides for earthworms.

The given list of pesticides included insecticides $(70 \%)$ and fungicides $(30 \%)$, in terms of the parameter $\mathrm{LC}_{50}$. The insecticide teflutrin ranks first in the rating of the acute toxicity of pesticides. The situation in terms of the parameter NOEC was quite different: insecticides $(50 \%)$, fungicides $(40 \%)$ and herbicides $(10 \%)$. In the rating of chronic toxicity, the fungicide epoxiconazole proved to be extremely hazardous for earthworms.

According to the hazard classification of chemicals for earthworms, the first class includes $3 \%$ of the pesticide active substances, the second class includes $13 \%$ of pesticide active substances, and $77 \%$ of the pesticide active substances belong to the third hazard class of acute toxicity.

Toxicity Assessment of Pesticides for Aquatic Organisms

We selected the 20 most toxic pesticides based on the minimum $\mathrm{LC}_{50} / \mathrm{EC}_{50}$ and NOEC upon the results of toxicity assessment of the pesticides for fish, aquatic invertebrates and algae. Figure 10 provides the ratings on the acute and chronic pesticide toxicity for aquatic organisms.
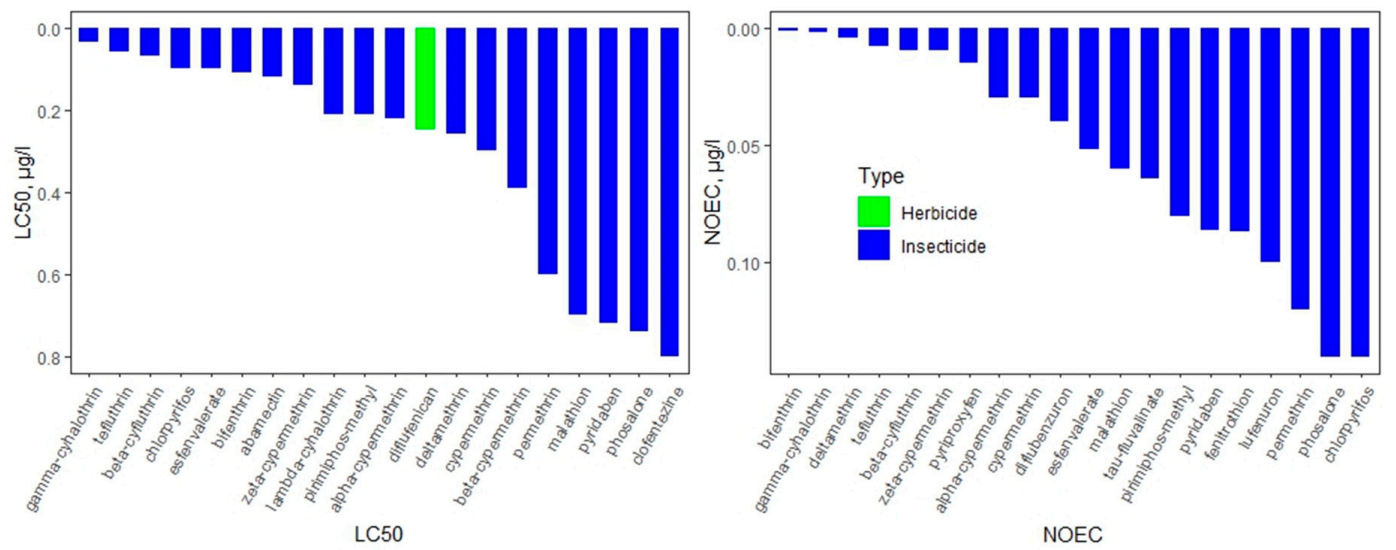

Figure 10. Ratings of the pesticide toxicity for the most sensitive group of aquatic organisms. 
The rating on acute toxicity included 19 insecticides and the herbicide diflufenican (Figure 10). Moreover, aquatic invertebrates significantly prevail among the most sensitive aquatic organisms. According to the hazard classifications of chemical products for a water medium, $69 \%$ of pesticide active substances of acute toxicity belong to the first class.

In terms of chronic toxicity, $45 \%$ of pesticide active substances have the hazard of the first class. Despite the fact that many pesticides belong to the first hazard class, the exposure of such hazard under the real conditions of pesticide application is not always observable and depends on pesticide concentration in water bodies.

\subsection{Accumulation of Pesticides in Aquatic Organisms and Earthworms}

The rating of pesticide bioconcentration in aquatic organisms shows that out of the 20 pesticides selected from 200 active substances, insecticides, herbicides, and fungicides constituted $70 \%, 20 \%$, and $10 \%$, respectively (Table 3 ).

Table 3. Rating of the pesticide bioconcentration in fish and earthworms.

\begin{tabular}{cccccc}
\hline Active Substance & Type & BCF Fish & Active Substance & Type & BCF Worms \\
\hline lufenuron & insecticide & 5300 & tau-fluvalinate & insecticide & 2630 \\
pendimethalin & insecticide & 5100 & bifenthrin & insecticide & 1000 \\
lambda-cyhalothrin & herbicide & 4982 & zeta-cypermethrin & insecticide & 1000 \\
esfenvalerate & insecticide & 3250 & tefluthrin & insecticide & 631 \\
famoxadone & insecticide & 3000 & pyridaben & insecticide & 589 \\
gamma-cyhalothrin & fungicide & 2240 & esfenvalerate & insecticide & 437 \\
clethodim & insecticide & 2100 & permethrin & insecticide & 316 \\
tau-fluvalinate & herbicide & 1979 & beta-cyfluthrin & insecticide & 200 \\
bifenthrin & insecticide & 1703 & alpha-cypermethrin & insecticide & 158 \\
oxyfluorfen & insecticide & 1637 & beta-cypermethrin & insecticide & 158 \\
propargite & herbicide & 1635 & chlorfluazuron & insecticide & 158 \\
fenpyroximate & insecticide & 1601 & propargite & insecticide & 126 \\
deltamethrin & insecticide & 1400 & cypermethrin & insecticide & 89 \\
tefluthrin & insecticide & 1400 & fenazaquin & insecticide & 81 \\
pyriproxyfen & insecticide & 1379 & lambda-cyhalothrin & insecticide & 79 \\
chlorpyrifos & insecticide & 1374 & proquinazid & fungicide & 79 \\
diflufenican & herbicide & 1276 & pendimethalin & herbicide & 63 \\
hexythiazox & insecticide & 1100 & pyriproxyfen & insecticide & 59 \\
fluazinam & fungicide & 1025 & imazamox & herbicide & 58 \\
tebufenpyrad & insecticide & 953 & lufenuron & insecticide & 33 \\
\hline
\end{tabular}

The rating of pesticide bioconcentration in earthworms, according to the data in Table 3 , shows that the maximum bioconcentration factor constituted $85 \%, 10 \%$, and $5 \%$ for insecticides, herbicides and fungicides, respectively.

Insecticides are highly accumulative both in earthworms and aquatic organisms. The ability to accumulate insecticides in tissues is associated with chemical affinity, i.e., the lipophilicity of a pesticide with organic substances.

Thus, after analyzing the results of pesticide rating in relation to the values of acute and chronic toxicity and $\mathrm{BCF}$, we proceed to the results of the risk calculation of pesticide negative impact.

\subsection{Risk of Pesticides Toxicity for Earthworms and Aquatic Organisms}

The calculation of acute toxicity exposure ratio (TER) has shown that all pesticides are classified as low risk negative impact on earthworms since $\mathrm{LC}_{50} / \mathrm{PEC}$ max. $>10$. The non-dimensional values of acute/long-term TER for earthworms are shown in Figure 11. 

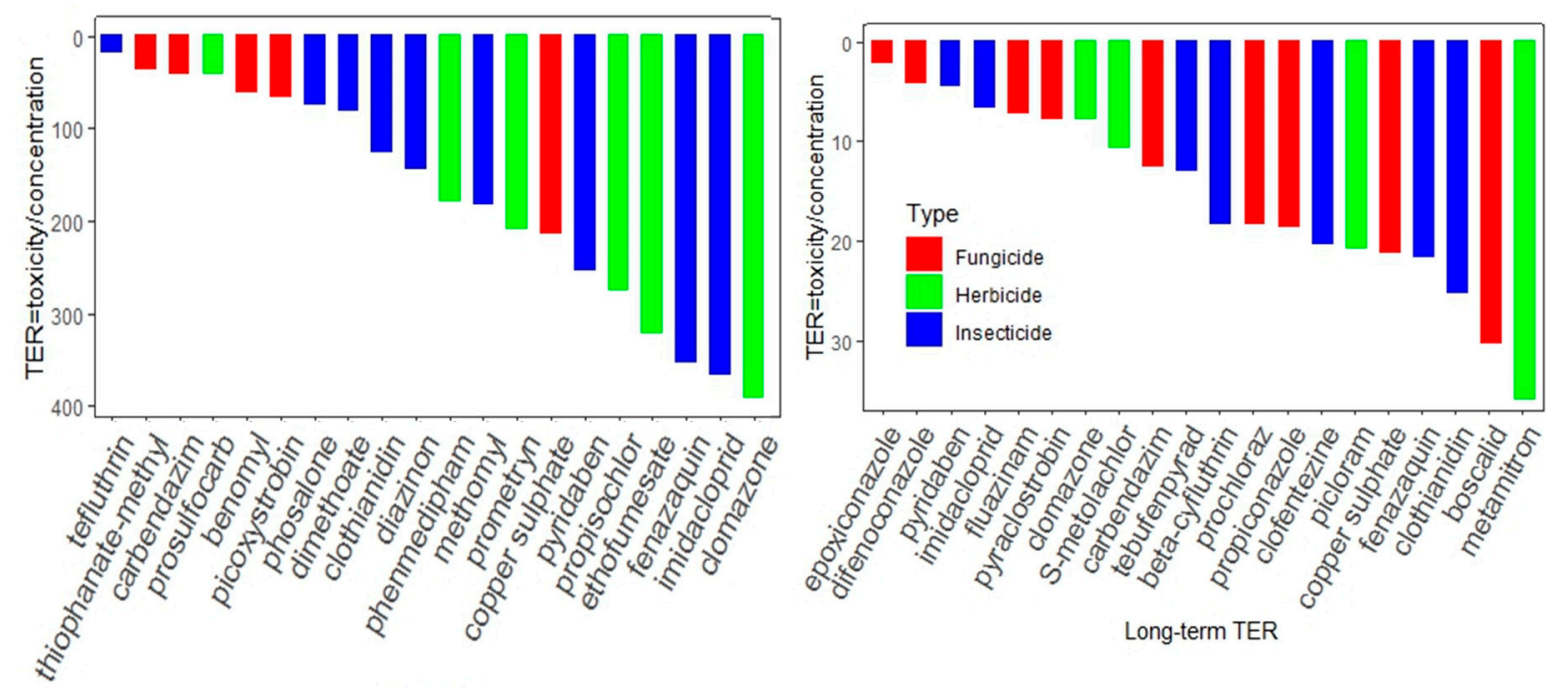

Acute TER

Figure 11. Ratings of the acute/long-term TER for earthworms.

Carbendazim fungicide takes third place in the pesticide rating of acute TER, as well as in acute toxicity in the previous rating. High long-term TER was found for three out of 200 pesticides: triazole fungicides of epoxiconazole, difenoconazole, and the insecticide pyridaben.

Risk of Pesticide Toxicity for Aquatic Organisms

Figure 12 shows the non-dimensional values of acute/long-term TER for the least resistant group of aquatic organisms (The selection of this group from three groups of hydrobionts was based on the following principle: a group was selected with the minimum numerical value of the ratio of toxicity to concentration, moreover, with a high risk of the pesticides' negative impact on aquatic organisms).
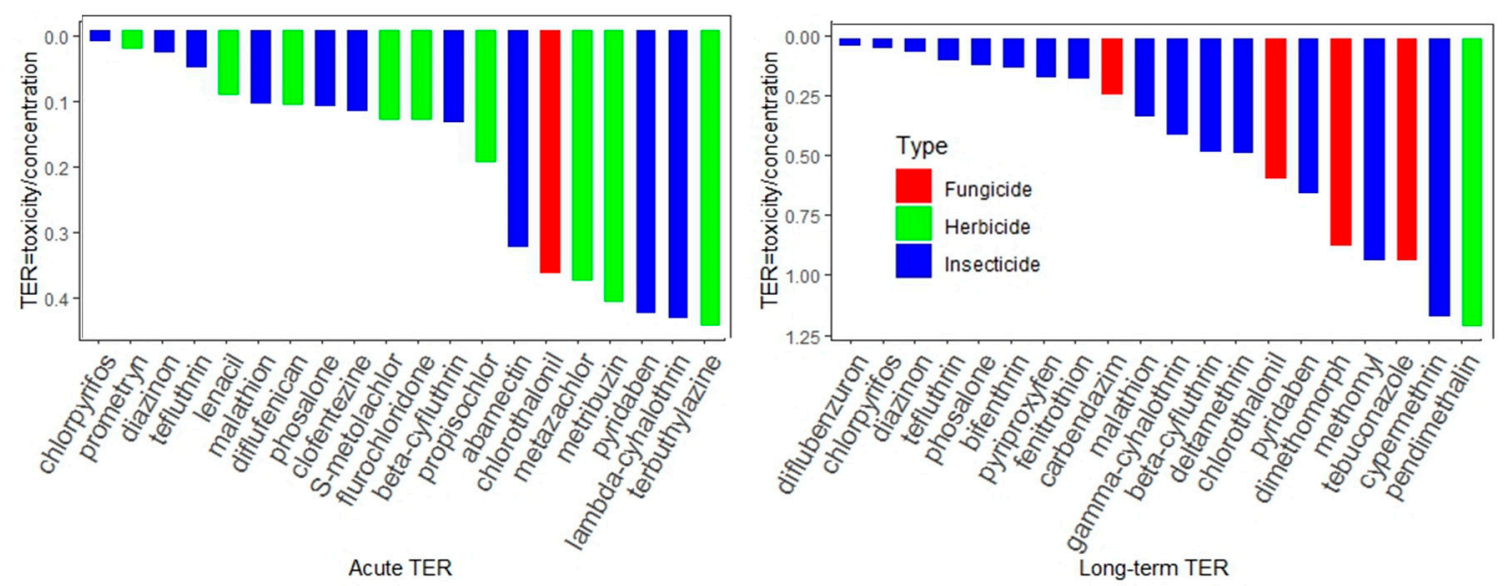

Figure 12. Ratings of the acute/long-term TER for aquatic organisms.

Insecticides prevailed in our ratings. Moreover, chlorpyrifos, diazinon and teflutrin are highly hazardous insecticides both in terms of acute toxicity risk and chronic toxicity risk.

\subsection{The Pesticide Risk Indicators for Earthworms and Aquatic Organisms}

The pesticide risk indicator is the sum of three parameters: the point expression of acute TER, point expression of long-term TER and the bioconcentration factor. The results of the study allowed us to calculate a risk indicator for each pesticide. Then, the pesticides were rated according to the value of the indicator (Figure 13). 


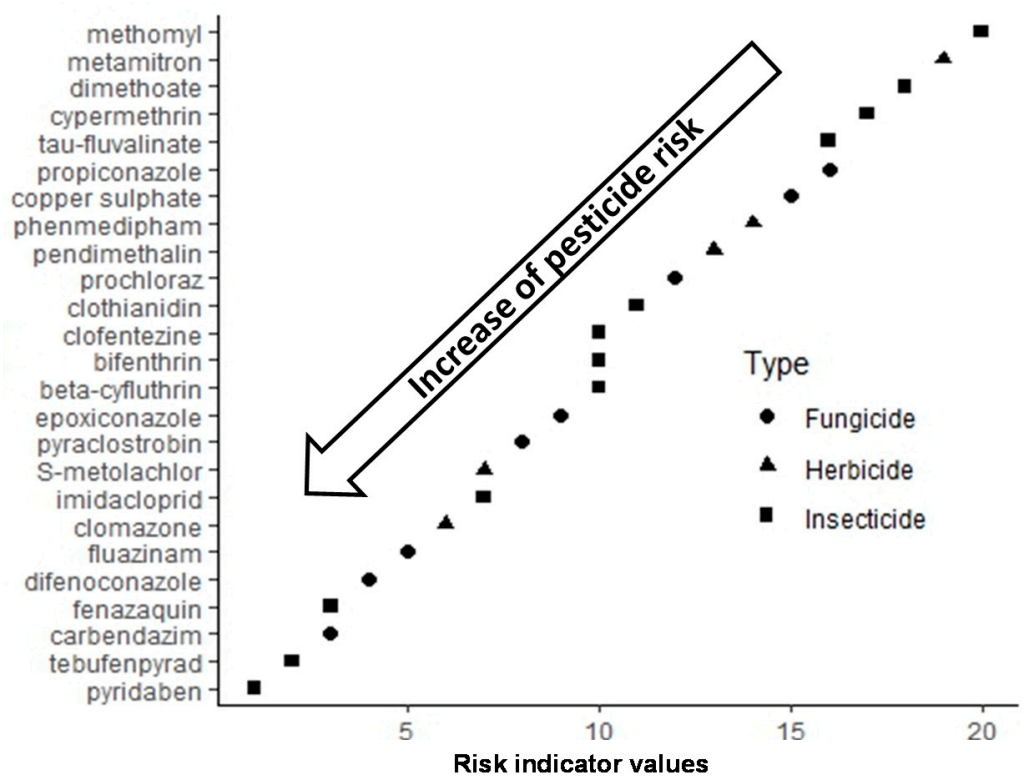

Figure 13. Rating of the pesticide risk indicators for earthworms.

Figure 13 shows that the lowest risk indicator corresponds to the greatest risk of pesticides' negative impact on earthworms. In general, the rating of pesticide risk indicators contains 20 positions which includes 25 pesticides: 12 insecticides, 8 fungicides and 5 herbicides (in three cases, two pesticides occupy the same line of the rating list, and in one case, three pesticides occupy the same line).

Figure 14 shows 19 insecticides, 4 herbicides and 1 fungicide, in the decreasing order of the pesticide risk indicators for aquatic organisms.

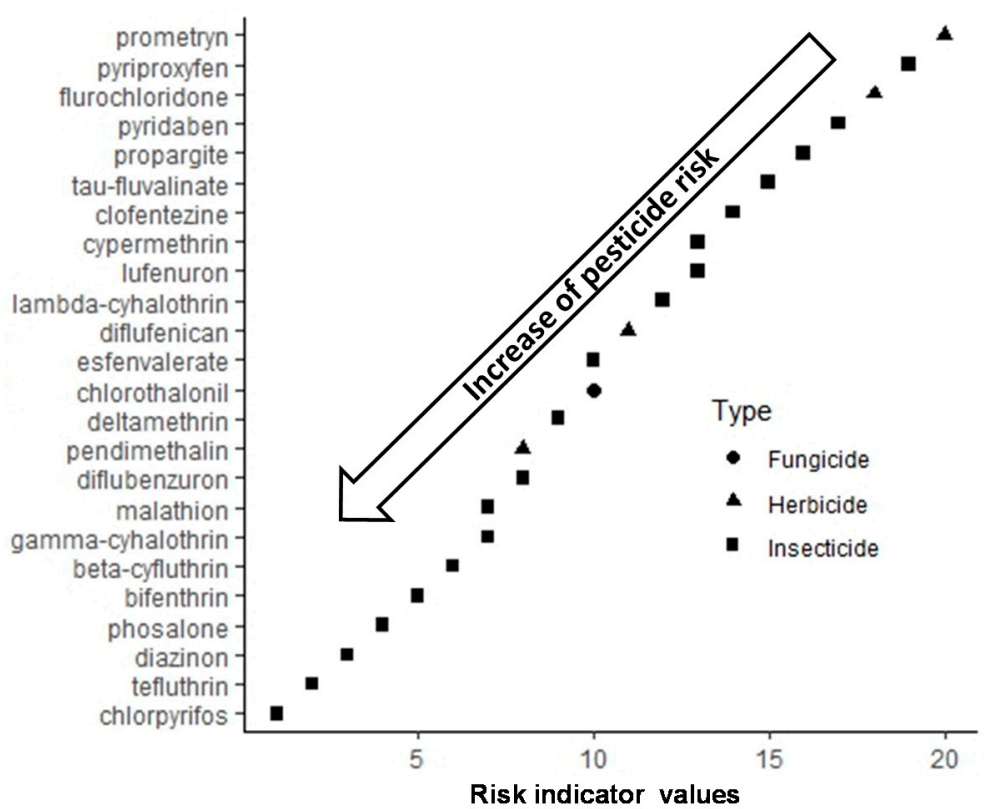

Figure 14. Rating of the pesticide risk indicators for aquatic organisms.

In this rating, three insecticides (chlorpyrifos, teflutrin and diazinon) with a maximum level of risk for aquatic organisms significantly outpaced other pesticides. Chlorpyrithis, teflutrin, and diazinon are extremely hazardous in terms of acute/long-term TER. 


\section{Discussion}

Prediction quality using the PEARL 4.4.4 model depends on its calibration [36]. The uncalibrated PEARL 4.4.4 overestimates the residual amount of metribuzin by $6-18 \%$ in the $0-20 \mathrm{~cm}$ layer on the 7 th, 14 th, and 28 th day, and underestimates the concentration of metribuzin by $8 \%$ on the 56 th day. In terms of the environmental risk assessment, such an overestimation reflects the "worst case" and is a permissible assumption [43]. It was previously shown that the STEP 1-2 model also overestimated the concentration of pesticides in water bodies compared to the actually measured values [44]. However, underestimating the pesticide residues, on the contrary, is an unacceptable assumption that can lead to serious environmental problems [45]. The work by Kroes et al. [46] shows that Koc DT 50 and the parameters of the van Genuhten equation have a greater effect on predicting the behavior of pesticides in soil. After the PEARL 4.4.4 calibration and the verification of prediction quality by statistical criteria, we achieved the satisfactory convergence of the calculated and experimental values of metribuzin concentration in soil.

According to the PEARL 4.4.4 prediction results, in the soils of the Moscow region, herbicides prevail in the first days after application. The high concentration of herbicides in the plow layer of soddy-podzolic soil is due to the higher rate of their application compared with fungicides and insecticides. At the same time, due to the higher resistance of fungicides to decomposition in soil (DT50 half-life $>60$ days), their content in 56 days after application is higher than for herbicides and insecticides. According to the prediction, herbicides also pollute surface water. For example, the herbicide metamitron is present in high concentrations both in soils and in surface waters. The migration of herbicides to water bodies, in addition to the high rates of their application, is contributed to by the low sorption and moderate resistance of the herbicides in the soil [39]. Herbicide migration is also caused by their use in the early development stages of protected crops. The results obtained are consistent with the previous studies. Simeonov L.I. et al. [47] also used the calculation method (but without mathematical models) and obtained the concentrations of 123 herbicides in surface water. The authors found that for herbicides in $80 \%$ of cases, more than half of their concentration of the recommended application rate may be in surface water bodies. Moreover, according to the monitoring of the Rotbach Creek river basin (Germany), firstly, herbicides were found, and secondly, the herbicide metamitron was detected at the highest concentration $(50 \mu \mathrm{g} / \mathrm{L})$ [48]. Thus, the conclusion that soils and surface waters will be mainly contaminated with herbicides is confirmed by the results of many researchers. In this regard, pesticide producers should change the regulation policy for the use of herbicides. For example, it may be a decrease in existing application rates or a modification of the herbicide formulations with organoclay (the herbicide molecule is adsorbed in the interplanar spacing of the organoclay so that migration ability of the pesticide is reduced) [49].

Insecticides prevail in the pesticide rating in terms of the values of acute and chronic toxicity for earthworms and aquatic organisms. Initially, acute and chronic toxicity for aquatic organisms was evaluated for three groups of aquatic organisms. For the further calculation of acute/long-term TER, the most sensitive group of aquatic organisms was selected. According to the compared results of toxicity values, aquatic invertebrates significantly prevail among the most sensitive aquatic organisms.

The results of the analysis and calculation of pesticide BCF have shown that insecticides will mainly accumulate in aquatic organisms and earthworms. The ability to accumulate insecticides in tissues is associated with chemical affinity, i.e., the lipophilicity of a pesticide with organic substances. Pesticide lipophilicity is measured with the xenibiotic octanol-water partition coefficient $\left(\mathrm{K}_{\mathrm{ow}}\right)$. The increase in $\mathrm{K}_{\mathrm{ow}}$ correlates with the probability of a pesticide penetrating the cell membrane. The correlation between this coefficient, $\mathrm{LC}_{50}$ and $\mathrm{BCF}$ is demonstrated in the publications devoted to pesticide bioaccumulation in earthworms [40,50]. Moreover, this was confirmed by the $\mathrm{K}_{\mathrm{ow}}$ rating of all active substances. Similar to the bioconcentration factor, the rating mainly included insecticides.

The calculation of acute TER for earthworms has shown that, all the pesticides have acute TER $>10$, except the insecticide teflutrin. The pyrethroid insecticide tefluthrin, as shown in the work by Rathore et al. [51] has a relatively high toxicity for earthworms (at $2 \mathrm{mg} / \mathrm{kg}$ soil). High long-term TER 
was found for three out of the 200 pesticides: triazole fungicides of epoxiconazole, difenoconazole, and the insecticide pyridaben. There is no evidence of a high chronic toxicity risk of these pesticides in the literature. Perhaps this is due to the fact that when calculating the risk of chronic toxicity, we used the maximum norms for the use of pesticides ("worst case"). However, in laboratory studies evaluating the toxicity of epoxiconazole for earthworms, Pelosi et al. [52] observed the sublethal effects of epoxiconazole on some earthworm species found in cultivated fields even at recommended rates, so that much more attention should be paid to this pesticide. The calculation results of acute TER for aquatic organisms have shown that chlorpyrifos, diazinon and teflutrin are highly hazardous insecticides, both in terms of acute toxicity and chronic toxicity. Thanh-Luu Phaml and Ha Manh Bui [53] also noted that the presence of diazinon in water bodies could be associated with significant risk to aquatic organisms.

The final outcome of this work was the environmental risk indicators. To calculate these indicators, we used three parameters: the point expression of acute TER, the point expression of long-term TER and the BCF. As a result, according to the values of environmental risk indicators, we compiled the ratings of soil and surface water pollutant pesticides. Pyridaben, tebufenpyrad and carbendazim are pesticides with a high risk of negative impact on earthworms. Chlorpyrifos, teflutrin and diazinon are pesticides with a high risk of negative impact on aquatic organisms. Moreover, the high risk of teflutrin and diazinon to aquatic organisms is confirmed by Munn et al. [54]. The authors calculated the toxicity indices of the pesticide toxicity index (PTI) for 129 pesticides and compared the calculated values with the real concentrations of pesticides in water.

Unlike existing risk indicators SYSCOR, PERI, ADSCOR, PTI, etc., our indicators have a number of advantages. Firstly, they are based on the mathematical modeling of pesticide concentrations in soil and surface waters. Secondly, a point-rating system was used to summarize the heterogeneous data. Thirdly, for a large number of pesticides, information about the potential risk of pesticides' negative impact can be obtained in short time without expensive and laborious experimental studies. Unlike scoring and a mechanistic model for input data transformation, our way of combining heterogeneous data groups into one indicator is simple and informative. Moreover, the results obtained can be used not only by pesticide producers, but also by the authorities in charge of pesticide registration. For example, they can change the use conditions of pesticides with high risk indicators.

Nevertheless, the proposed pesticide risk indicators have several limitations which should be carefully considered in application. First, this concerns regions with high soil diversity since the obtained values may vary. In addition, the potentially different sensitivity of non-target organisms to a pesticide can introduce uncertainty into data interpretation compared to the sensitivity of test organisms. The utility of the pesticide indicators for earthworms and aquatic organisms will be determined by testing the correlation of indicator values with various measures of the nature and health of earthworms and aquatic biota.

\section{Conclusions}

The pesticide risk indicator is the sum of three parameters: point expression of acute TER, point expression of long-term TER and BCF. The ratings of soil and surface water pesticides were compiled according to the values of environmental risk indicators. Pyridaben, tebufenpyrad and carbendazim were found to be the pesticides with a high risk of negative impact on earthworms. Chlorpyrifos, teflutrin and diazinon were found to be the pesticides with a high risk of negative impact on aquatic organisms. Pesticide producers and monitoring authorities can be provided with recommendations on risk reduction measures of these pesticides.

The proposed risk indicators of pesticides' negative impact on earthworms and aquatic organisms have the following benefits: first, their calculation used the data of the mathematical prediction model of pesticide concentration in soil and water; second, specific features of pesticide transformation and pesticide migration in specific soil-climate conditions were considered; third, the acute and chronic pesticide toxicity for a non-target organism and pesticide bioaccumulation in its tissues were 
estimated. Thus, the developed risk indicator considers both the toxicity of pesticides' active substance and its behavior in the environment. At the same time, the proposed risk indicator may have a number of limitations for its application, primarily for the regions with high soil diversity so that the results of mathematical modeling will depend on the model calibration for the SWRC of soils in these regions. In addition, as opposed to the sensitivity of test organisms, the potentially different sensitivity of non-target organisms to pesticides can result in the uncertainty of data interpretation. Nevertheless, the proposed risk indicator can be used to manage the pesticide risks considering region-specific conditions.

Supplementary Materials: The following are available online at http://www.mdpi.com/2073-4395/10/8/1070/s1, Table S1: Parameters of the soddy-podzolic soil, Table S2: Physicochemical and eco-toxicological properties of pesticides, Table S3: Metribuzin residual amount in soddy-podzolic soil, Table S4: PEC in soil and surface water.

Author Contributions: Conceptualization, A.A. and M.M.; methodology, R.S. and V.G.; software, A.A.; validation, A.A., E.K.; formal analysis, A.A.; investigation, A.A. and R.S.; resources, R.S. and V.G.; data curation, A.A.; writing-original draft preparation, M.M. and S.K.; writing—review and editing, A.A.; visualization, A.A.; supervision, M.M. and V.G.; project administration, A.A.; funding acquisition, R.S. and V.G. All authors have read and agreed to the published version of the manuscript.

Funding: This research was funded by the Russian Foundation for Basic Research (project No 18-016-00130).

Conflicts of Interest: The authors declare no conflict of interest.

\section{References}

1. Sharma, A.; Kumar, V.; Shahzad, B.; Tanveer, M.; Sidhu, G.P.S.; Handa, N.; Kohli, S.; Yadav, P.; Bali, A.S.; Parihar, R.D.; et al. Worldwide Pesticide Usage and Its Impacts on Ecosystem. SN Appl. Sci. 2019. Available online: https://doi.org/10.1007/s42452-019-1485-1 (accessed on 1 May 2020). [CrossRef]

2. Astaykina, A.A.; Streletskii, R.A.; Maslov, M.N.; Belov, A.A.; Gorbatov, V.S.; Stepanov, A.L. The Impact of Pesticides on the Microbial Community of Agrosoddy-Podzolic Soil. Eurasian Soil Sci. 2020. [CrossRef]

3. Topping, C.J.; Aldrich, A.; Berny, P. Overhaul Environmental Risk Assessment for Pesticides. Science 2020. Available online: https://www.ncbi.nlm.nih.gov/pubmed/31974232 (accessed on 1 May 2020). [CrossRef] [PubMed]

4. Handford, C.E.; Elliott, C.T. A Review of the Global Pesticide Legislation and the Scale of Challenge in Reaching the Global Harmonization of Food Safety Standards. Integr. Environ. Assess Manag. 2015. Available online: https://www.ncbi.nlm.nih.gov/pubmed/25765969 (accessed on 1 May 2020). [CrossRef] [PubMed]

5. Alix, A.; Knauer, K.; Streloke, M.; Poulsen, V. Development of a Harmonized Risk Mitigation Toolbox Dedicated to Environmental Risks of Pesticides in Farmland in Europe: Outcome of the Magpie Workshop; Julius Kühn Institut, Bundesforschungsinstitut für Kulturpflanzen: Quedlinburg, Sweden, 2015.

6. Boivin, A.; Poulsen, V. Environmental Risk Assessment of Pesticides: State of the Art and Prospective Improvement from Science. Environ. Sci. Pollut. Res. Int. 2017. Available online: https://www.ncbi.nlm.nih. gov/pubmed/28039636 (accessed on 1 May 2020). [CrossRef] [PubMed]

7. Kegley, S.E.; Hill, B.R.; Orme, S.; Choi, A.H. Pan Pesticide Database; Pesticide Action Network, North America: Oakland, CA, USA, 2016; Available online: http://www.pesticideinfo.org (accessed on 1 May 2020).

8. Jager, T.; Albert, C.; Thomas, G.P.; Ashauer, R. General Unified Threshold Model of Survival-a Toxicokinetic-Toxicodynamic Framework for Ecotoxicology. Environ. Sci. Technol. 2011, 45, 2529-2540. [CrossRef]

9. Van der Voet, H.; de Boer, W.J.; Kruisselbrink, J.W.; Goedhart, P.W.; van der Heijden, G.W.A.M.; Kennedy, M.C.; Boon, P.E.; van Klaveren, J.D. The MCRA Model for Probabilistic Single-Compound and Cumulative Risk Assessment of Pesticides. Food Chem. Toxicol. 2015. Available online: http://www.sciencedirect.com/science/ article/pii/S0278691514004360 (accessed on 1 May 2020). [CrossRef] [PubMed]

10. Ashauer, R.; Albert, C.; Augustine, S.; Cedergreen, N.; Charles, S.; Ducrot, V.; Focks, A.; Gansi, F.; Gergs, A.; Goussen, B.; et al. Modelling Survival: Exposure Pattern, Species Sensitivity and Uncertainty. Sci. Rep. 2016. Available online: https://www.ncbi.nlm.nih.gov/pubmed/27381500 (accessed on 6 June 2016). [CrossRef]

11. Moshe, C.; Wajnberg, E. Environmental Pest Management: Challenges for Agronomists, Ecologists, Economists and Policymakers; John Wiley \& Sons: Hoboken, NJ, USA, 2017. 
12. Lise, S.-P.; Bøje, C.; Hansen, L.F.; Kjølholt, J.; Jørgensen, L.N.; Kudsk, P.N.; Ørum, J.E. The Agricultural Pesticide Load in Denmark 2007-2010; Miljøstyrelsen: København, Denmark, 2012.

13. Per, K.; Jørgensen, L.N.; Ørum, J.E. Pesticide Load-A New Danish Pesticide Risk Indicator with Multiple Applications. Land Use Policy 2018, 70, 384-393.

14. Sabrina, G.; Gabriel, E.; Chadœuf, J.; Bonneu, F.; Bretagnolle, V. Herbicides Do Not Ensure for Higher Wheat Yield, but Eliminate Rare Plant Species. Sci. Rep. 2016, 6, 1-10.

15. Perry, E.D.; Ciliberto, F.; Hennessy, D.A.; Moschini, G. Genetically Engineered Crops and Pesticide Use in Us Maize and Soybeans. Sci. Adv. 2016, 2, e1600850. [CrossRef] [PubMed]

16. Martin, L.; Dessaint, F.; Py, G.; Makowski, D.; Munier-Jolain, N. Reducing Pesticide Use While Preserving Crop Productivity and Profitability on Arable Farms. Nat. Plants 2017, 3, 1-6.

17. Van Bol, V.; Debongnie, P.; Pussemier, L.; Maraite, H.; Steurbaut, W. Study and Analysis of Existing Pesticide Risk Indicators-Task B1; Veterinary and Agrochemical Research Center (VAR): Teruren, Belgium, 2002; p. 38.

18. Stewart, P.W. Pesticide Use in California: Strategies for Reducing Environmental Health Impacts; CPS Report; California Policy Seminar, University of California: Berkeley, CA, USA, 1996.

19. Swanson, M.B.; Davis, G.A.; Kincaid, L.E.; Schultz, T.W.; Bartmess, J.E.; Jones, S.L.; George, E.L. A Screening Method for Ranking and Scoring Chemicals by Potential Human Health and Environmental Impacts. Environ. Toxicol. Chem. An Int. J. 1997, 16, 372-383. [CrossRef]

20. Higley, L.G.; Wintersteen, W.K. A Novel Approach to Environmental Risk Assessment of Pesticides as a Basis for Incorporating Environmental Costs into Economic Injury Levels. Am. Entomol. 1992, 38, 34-39. [CrossRef]

21. Hornsby, A.G.; Buttler, T.M.; Brown, R.B. Managing Pesticides for Crop Production and Water Quality Protection: Practical Grower Guides. Agric. Ecosyst. Environ. 1993, 46, 187-196. [CrossRef]

22. Van der Werf, H.M.G. Assessing the Impact of Pesticides on the Environment. Agric. Ecosyst. Environ. 1996. Available online: http://www.sciencedirect.com/science/article/pii/S0167880996010961 (accessed on 1 December 1996). [CrossRef]

23. Levitan, L. An Overview of Pesticide Impact and Risk Assessment Systems; Cornell University: Ithaca, NY, USA, 1997.

24. Hart, A. Key Characteristics of Pesticide Risk Indicators Used as Policy Tools: A Comparison of 11 Indicators. In Proceedings of the OECD Workshop on Pesticide Risk Indicators 30, Copenhagen, Denmark, 21-23 April 1997.

25. Falconer, K. Classification of Pesticides According to Environmental Impact; Centre for Rural Economy; University of Newcastle-Upon-Tyne: Newcastle, UK, 1998.

26. Reus, J.; Leendertse, P.; Bockstaller, C.; Fomsgaard, I.; Gutsche, V.; Lewis, K.; Nilsson, C.; Pussemier, L.; Trevisan, M.; van der Werf, H.; et al. Comparison and Evaluation of Eight Pesticide Environmental Risk Indicators Developed in Europe and Recommendations for Future Use. Agric. Ecosyst. Environ. 2002, 90, 177-187. [CrossRef]

27. Kogan, M. Integrated Pest Management: Historical Perspectives and Contemporary Developments. Annu. Rev. Entomol. 1998, 43, 243-270. [CrossRef]

28. Greitens, T.J.; Day, E. An Alternative Way to Evaluate the Environmental Effects of Integrated Pest Management: Pesticide Risk Indicators. Renew. Agric. Food Syst. 2007, 22, 213-222. [CrossRef]

29. Spikkerud, E. Pesticide Aquatic Risk Indicators: Testing the OECD Indicators Rextox, Adscor and Syscor and the Norwegian Aquatic Risk Indicator with Estimates of Use Data from Norway; Technical Report of the OECD; Organisation for Economic Co-operation: Paris, France, 2002; Available online: https://www.oecd.org/env/ ehs/pesticides-biocides/2752913.pdf (accessed on 1 May 2020).

30. Den, H.; Groenewegen, F.P.; van Straalen, N. Pesticides: Problems, Improvements, Alternatives; John Wiley \& Sons: Hoboken, NJ, USA, 2008.

31. Möhring, N.; Hirsch, S.; Bozzola, M.; Finger, R. Revisiting Risk Effects of Pesticides Evidence from Swiss Wheat Production; Mimeo AECP Group; ETH Zürich: Zürich, Switzerland, 2019.

32. Muhammetoglu, A.; Durmaz, S.; Uslu, B. Evaluation of the Environmental Impact of Pesticides by Application of Three Risk Indicators. Environ. Forensics 2010, 11, 179-186. [CrossRef]

33. European Commission Leaching Models and EU Registration (Final Report of the Work of the Focus); EU-DOC 4952/VI/95: Brussels, Belgium, 1995; Available online: http://europa.eu.int/comm/food/fs/ph_ps/pro/wrkdoc/ focus/gw_en.pdf (accessed on 1 May 2020). 
34. Van den Berg, F.; Tiktak, A.; Boesten, J.J.T.I.; van der Linden, A.M.A. Pearl Model for Pesticide Behaviour and Emissions in Soil-Plant Systems. Statut. Res. Tasks Unit Nat. Environ. 2016. Available online: https://edepot.wur.nl/377664 (accessed on 1 May 2020).

35. Surface Water Tool for Exposure Predictions-Step 1 and Step 2-Developed by the FOCUS Surface Water Groop. Version 3.2. Available online: https://esdac.jrc.ec.europa.eu/projects/stepsonetwo (accessed on 1 June 2020).

36. Scorza, J.; Rômulo, P.; da Silva, J.P. Sensibility Analysis of the Pearl Model for Pesticide Leaching in the State of Mato Grosso Do Sul, Brazil. Eng. Agrícola 2011, 31, 965-973. [CrossRef]

37. Shein, E.V.; Kokoreva, A.A.; Gorbatov, V.S.; Umarova, A.B.; Kolupaeva, V.N.; Perevertin, K.A. Sensitivity Assessment, Adjustment, and Comparison of Mathematical Models Describing the Migration of Pesticides in Soil Using Lysimetric Data. Eurasian Soil Sci. 2009, 42, 769-777. [CrossRef]

38. Lewis, K.A.; Douglas, J.T.; Warner, J.; Green, A. An International Database for Pesticide Risk Assessments and Management. Hum. Ecol. Risk Assess. An Int. J. 2016, 22, 1050-1064. [CrossRef]

39. PPDB. Available online: http://sitem.herts.ac.uk/aeru/footprint/index2.htm (accessed on 1 June 2020).

40. Connell, D.W.; Markwell, R.D. Bioaccumulation in the Soil to Earthworm System. Chemosphere 1990, 20, 91-100. [CrossRef]

41. EFSA Panel on Plant Protection Products and their Residues. Guidance on Tiered Risk Assessment for Plant Protection Products for Aquatic Organisms in Edge-of-Field Surface Waters. EFSA J. 2013, 11, 3290.

42. European and Mediterranean Plant Protection Organization [EPPO]. Decision-making scheme for the environmental risk assessment of plant protection products. Bull OEPP/EPPO Bull 1993, 23, 1-165. [CrossRef]

43. Suter, G.W., II. Ecological Risk Assessment; CRC Press: Boca Raton, FL, USA, 1992.

44. Knabel, A.; Stehle, S.; Schahafer, R.; Schulz, R. Regulatory FOCUS surface water models fail to predict insecticide concentration in the field. Environ. Sci. Technol. 2012, 46, 8397-8404. [CrossRef]

45. Nicolopoulou-Stamati, P.; Maipas, S.; Kotampasi, C.; Stamatis, P.; Hens, L. Chemical pesticides and human health: The urgent need for a new concept in agriculture. Front. Public Health 2016, 4, 148. [CrossRef]

46. Kroes, J.G.; van Dam, J.C.; Groenendijk, P.; Hendriks, R.F.A.; Jacobs, C.M.J. Theory Description and User Manual, 3.2th ed.; Alterra report; No. 1649(02); Alterra: Wageningen, The Netherlands, 2009.

47. Simeonov, L.I.; Macaev, F.Z.; Simeonova, B.G. Environmental Security Assessment and Management of Obsolete Pesticides in Southeast Europe; Springer: Berlin/Heidelberg, Germany, 2014.

48. Christoffels, E. The Importance of Soil Erosion for Surface Waters in the Case of Rotbach Creek. In WIT Transactions on Ecology and the Environment; WIT Press: Ashurst, UK, 2016; pp. 1-14.

49. Polubesova, T.; Nir, S.; Gerstl, Z.; Borisover, M.; Rubin, B. Imazaquin Adsorbed on Pillared Clay and Crystal Violet-Montmorillonite Complexes for Reduced Leaching in Soil. J. Environ. Qual. 2002, 31, 1657-1664. [CrossRef]

50. Toshiyuki, K.; Ose, K. Toxicity, Bioaccumulation and Metabolism of Pesticides in the Earthworm. J. Pestic. Sci. 2015, 40, 69-81.

51. Rathore, H.S.; Leo, M.L. Nollet. Pesticides: Evaluation of Environmental Pollution; CRC Press: Boca Raton, FL, USA, 2012.

52. Pelosi, C.; Lebrun, M.; Beaumelle, L.; Cheviron, N.; Delarue, G.; Nelieu, S. Sublethal Effects of Epoxiconazole on the Earthworm Aporrectodea Icterica. Environ. Sci. Pollut. Res. 2016, 23, 3053-3061. [CrossRef] [PubMed]

53. Pham, T.-L.; Bui, H.M. Comparison of Diazinon Toxicity to Temperate and Tropical Freshwater Daphnia Species. J. Chem. 2018. [CrossRef]

54. Munn, M.D.; Gilliom, R.J.; Moran, P.W.; Nowell, L.H. Pesticide Toxicity Index for Freshwater Aquatic Organisms. US Department of the Interior; US Geological Survey: Reston, VA, USA, 2006; p. 81.

(C) 2020 by the authors. Licensee MDPI, Basel, Switzerland. This article is an open access article distributed under the terms and conditions of the Creative Commons Attribution (CC BY) license (http://creativecommons.org/licenses/by/4.0/). 